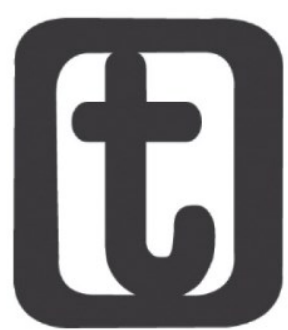

\title{
CONSERVADORISMO E LAICIDADE DE ESTADO: SUBSÍDIOS PARA O DEBATE NO SERVIÇO SOCIAL
}

\author{
Conservatism and laity of state: subsidies for the debate in the social work
}

\author{
Priscila Fernanda Gonçalves Cardoso* \\ Luciano Alves**
}

\begin{abstract}
RESUMO
O presente artigo apresenta a relação entre conservadorismo, laicidade do Estado e do exercício profissional, a partir de revisão bibliográfica e análise documental, apontando os desafios postos ao Projeto Ético-Político no enfrentamento deste debate e na luta contra o conservadorismo na atualidade. Considera-se que o componente ético-político trabalhado na perspectiva de resgatar a laicidade de Estado e do exercício profissional, compreende um grande facilitador no processo de contraposição ao conservadorismo e à lógica burguesa de dominação. Demonstra-se, portanto, a necessidade de aprofundamento deste debate no interior do Serviço Social como coerência ética com o Projeto Ético-Político, assumindo a perspectiva da defesa da liberdade e dos direitos humanos em sua radicalidade.
\end{abstract}

\section{PALAVRAS-CHAVES}

Conservadorismo. Laicidade do Estado. Religião. Serviço Social. Ética Profissional.

\section{ABSTRACT}

This article presents the relationship between conservatism, laity of state and laity of professional practice, based on a bibliographical review and documentary analysis, pointing out the challenges posed to the Ethical-Political Project in facing this debate and in the struggle against conservatism today. It is considered that the ethicalpolitical component worked with the perspective of rescuing the laity of State and the professional exercise, comprises a great facilitator in the process of contraposition to conservatism and the bourgeois logic of domination. It demonstrates, therefore, the need to deepen this debate within the Social Work as ethical coherence with the Ethical-Political Project, assuming the perspective of the defense of freedom and human rights in its radicality.

\section{KEYWORDS}

Conservatism. Laity of State. Religion. Social Work. Professional Ethics.

Submetido em: 30/9/2018.

Aceito em: 20/12/2018.

* Doutora em Serviço Social pela Pontifícia Universidade Católica de São Paulo (PUC/SP). Docente do Curso de Serviço Social e do Programa de Pós Graduação em Serviço Social e Política Social da Universidade Federal de São Paulo (UNIFESP, São Paulo, Brasil). ORC ID: <https://orcid.org/0000-0002-3524-7623>. E-mail: <prifgcardoso@gmail.com>.

** Assistente Social. Mestre em Serviço Social. Assistente social na Defensoria Pública do Estado de São Paulo. Conselheiro Estadual do Conselho Regional de Serviço Social de São Paulo (CRESS/SP) gestão 2017-2020. ORC ID: <https://orcid.org/0000-0002-3704-2891>.E-mail: <lucianoalves.76@gmail.com>.

DOI 10.22422/temporalis.2018v18n36p45-64 


\section{temporalis}

\section{INTRODUÇÃO}

O presente artigo nasce do encontro dos dois autores, em 2016, em palestra para Semana do Serviço Social da Universidade Federal de São Paulo. Ao apresentarem suas discussões sobre conservadorismo e a laicidade do Estado/exercício profissional, abre-se a possibilidade de um frutífero debate no qual se percebe a complementaridade das perspectivas e abordagens. Surge ali, o desejo de produzir um material conjuntamente.

Dois anos depois, diante do tema apresentado por esta revista, tendo os dois aprofundado seus debates acerca da temática, realiza-se o desejo materializando-o neste artigo como fruto de pesquisa teórica, a partir de revisão bibliográfica e o diálogo com a legislação profissional.

Tendo como objetivo problematizar e contribuir com o debate acerca da importância da defesa da laicidade do exercício profissional e do Estado, o artigo apresenta em sua primeira parte uma retomada dos fundamentos do conservadorismo moderno a partir da reconstrução dos valores defendidos desde sua gênese no século XVIII. Propõe, então, reflexão sobre a conjuntura atual demonstrando que o conservadorismo nunca esteve acabado e apresenta na atualidade, em níveis mundiais, um processo de radicalização traduzido nas diferentes expressões de ódio e intolerância.

Trazendo as expressões do conservadorismo moderno para a leitura da atualidade, a segunda parte do trabalho discute os elementos básicos de caracterização da laicidade de Estado, desde o lastro da secularização, passando pela a definição de Separação entre Estado e Clero, da Liberdade Religiosa, da Liberdade de Consciência até a demonstração de exemplos geopolíticos que explicitam a situação desse pressuposto emancipatório, enquanto herança das revoluções francesa e industrial e os tensionamentos postos neste debate.

Expõe, também, elementos analíticos do formato básico da laicidade do Estado brasileiro, espelhando criticamente nos modelos constitucionais desde a República Velha até as incursões e polêmicas abertas pelos governos federais desde a redemocratização aos dias atuais, desafiando a legitimidade da República, ainda que nos seus limites burgueses.

Um afunilamento propício ao debate da laicidade profissional, no Serviço Social, é apresentado na terceira e última parte do trabalho, no escopo de afirmar a coerência ética da defesa da laicidade de Estado como importante instrumento de padrão civilizatório político e democrático que situa a profissão imbricada na necessidade de materialização de seu Projeto Ético-Político sem, ao mesmo tempo, abdicar de sua indignação perante o atual retrocesso conservador no campo político e institucional, em face dos desafios postos nos espaços sociocupacionais, bem como perante o princípio fundamental da defesa da liberdade como valor ético central do ser social e sua intrínseca raiz na emancipação política e humana. 


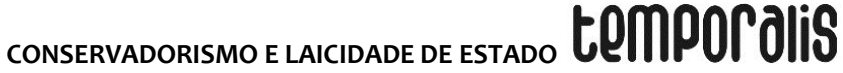

\section{OS FUNDAMENTOS DO CONSERVADORISMO MODERNO E SUA EXPRESSÃO NA ATUALIDADE}

A discussão da laicidade do Estado no Brasil, e consequentemente, de suas instituições e dos espaços públicos de atendimento a população alvo das políticas sociais - o que nos diz respeito diretamente enquanto assistentes sociais - remete-nos necessariamente a retomada do pensamento conservador, numa conjuntura de radicalização dessa perspectiva que ataca direitos, produz ódio e destrói políticas.

Nesse sentido, retomamos aqui alguns elementos centrais dos fundamentos deste pensamento em sua raiz, a partir de sua elaboração expressa na obra de Edmund Burke ${ }^{1}$ (século XVIII), considerado fundador do conservadorismo moderno.

O pensamento conservador é uma postura política e ética que se desenvolve como reação crítica à revolução francesa e industrial, aos defensores da igualdade e liberdade, bem como aos movimentos socialistas/organização dos trabalhadores. Um pensamento, portanto, de crítica à modernidade, à constituição da sociedade burguesa e à perspectiva emancipatória, defendendo valores presentes no período pré-revoluções.

A afirmação destes valores tem como base a defesa da tradição, entendendo que todo conhecimento provém da experiência, e que qualquer perspectiva de mudança desconsidera os acúmulos de tal experiência. Neste sentido, ao mesmo tempo, apresenta-se como uma crítica à razão moderna e às perspectivas revolucionárias. Nas palavras de Burke, "[...] geralmente um espírito de inovação é o resultado de um temperamento egoísta e de concepções estreitas" (BURKE, 2001, p. 33).

A defesa da liberdade e igualdade, centrais na revolução francesa, é vista como falácia e irrealizável diante de uma visão de sociedade na qual a desigualdade é compreendida como natural e essencial à harmonia social.

Nisso consiste a autêntica igualdade moral da humanidade e não naquela ficção monstruosa que, ao inspirar ideias falsas e vãs expectativas nos homens destinados a viajar no passo obscuro da vida laboriosa, apenas se presta a agravar e a amargar aquela desigualdade real que nunca se pode eliminar e que a ordem da vida civil estabelece tanto para o benefício daqueles a quem ela deve deixar num estado humilde quanto para aqueles a quem é capaz de exaltar a uma condição notável mas não mais feliz (BURKE, 2001. p. 38).

Ao defender a tradição e compreender a sociedade como naturalmente desigual e hierarquizada numa similaridade com a natureza, afirma a interdependência entre os indivíduos que devem buscar a cooperação entre si. É necessário, para tanto, que regras sejam criadas a fim de promover tal cooperação, mantendo a ordem, a autoridade, a disciplina e justificando o uso da repressão caso seja necessário. Tais regras sociais serão consequência

\footnotetext{
${ }^{1}$ Situam-se como importantes referências deste pensamento em sua origem, além de Edmund Burke (Inglaterra), Joseph de Maistre, Bonald e Lamennais (França).
} 
das leis divinas, uma vez que tanto o Estado quanto a sociedade, como parte da natureza, devem seguir as ordens do Universo enquanto criações divinas que são.

Como pilares da defesa destes valores e da tradição, estão outros três elementos estruturantes da sociedade: a propriedade privada, a família e a Igreja, as duas últimas vistas como corporações naturais responsáveis pela manutenção da ordem, da hierarquia e da reprodução dos valores e regras sociais. A família tem ainda, o papel fundamental de manutenção da propriedade privada nos processos de herança, garantindo a continuidade da desigualdade (compreendida como natural e fundamental) entre grupos e classes sociais.

Segundo Burke, Deus criou um Universo ordenado, governado por leis eternas. Os homens são parte da natureza e estão sujeitos às suas leis. Estas leis eternas criam suas convenções e o imperativo de respeitá-las; regulam a dominação do homem pelo homem e controlam os direitos e obrigações dos governantes e governados. Os homens, por sua vez, dependem uns dos outros e sua ação criativa e produtiva se desenvolve através da cooperação. Esta requer a definição de regras e confiança mútua, o que é desenvolvido pelos homens, com o passar do tempo, através da interação, da acomodação mútua e da adaptação ao meio em que vivem (KINZO, 2001, p. 20).

Destarte, na gênese do pensamento conservador encontra-se a concepção do Estado como legado de Deus, portanto, mais do que uma articulação, uma condição do Estado. Há uma unidade entre Estado e fé, o que nos diz historicamente do poder político da Igreja Católica durante séculos e, mesmo após o processo de secularização, o arraigado imbricamento entre a religião, o Estado e suas instituições.

A partir deste breve resgate acerca dos elementos centrais que constituem o pensamento conservador em sua gênese, podemos afirmar que o mesmo atravessou séculos. Embora tenhamos avançado na conquista dos direitos humanos e de níveis civilizatórios pautados na defesa de valores emancipatórios, a existência do pensamento conservador esteve sempre pressionando e ganhando diferentes formas em nossas sociedades. Engana-se quem o supôs acabado! Podemos falar em momentos de avanços e retrocessos e, explicitamente, vivemos mundialmente um dos momentos de avanço das ideias conservadoras.

No rastro de radicalização do conservadorismo, evidenciam-se ações concretas de expressão do ódio e da intolerância a tudo o que se contrapõe aos pilares desse pensamento. São evocadas intransigentemente a autoridade, a hierarquia, a ordem, a repressão e a disciplina, em nome da família, da tradição e da igreja. Nesse clima, intensificam-se os ataques a direitos conquistados, ameaça-se os pilares da democracia, ataca-se tudo o que é visto e entendido como risco à ordem e harmonia social. Assim, gays, lésbicas, negros/as, transgêneros, religiões de matriz africana, comunistas, socialistas, presos/as, pobres, mulheres, entre outros/as, são vistos/as como ameaças a serem exterminadas com repressão, violência e disciplina. Instaurase a defesa do justiçamento com as próprias mãos, evoca-se a punição e o sofrimento (CARDOSO, 2016, p. 103). 
O conservadorismo tem na lógica de opressão/exploração própria do capitalismo-patriarcalracista ${ }^{2}$ os elementos para sua manutenção e radicalização, e encontra "[...] condições favoráveis para se desenvolver em momentos de crise social, exercendo a função de enfren-tamento das tensões e contradições sociais e contribuindo, direta ou indire-tamente, para a apologia do capitalismo" (BARROCO, 2015, p. 624).

A crise mundial de 2008 tem na extrema-direita respostas com adesão de grande parte da população em todo o mundo, retomando o pensamento conservador em sua radicalidade. $\mathrm{Na}$ Europa, as eleições na última década explicitam o avanço da extrema-direita como não se via desde os anos de 1930 (LÖWY, 2015), o mesmo ocorre nos EUA com a eleição de Trump. Na América Latina explicita-se a polarização dos projetos emancipatórios (em suas diferenças na esquerda) e do conservadorismo (enraizado na direita e ecoando no discurso de ódio e fobias na extrema-direita).

No Brasil, vimos vivendo um processo de legitimação do conservadorismo que se expressa na constituição de uma forte e articulada bancada evangélica no Congresso e Senado, na criminalização da pobreza, culpabilização dos/as trabalhadores/as, regressão dos direitos, ataque aos movimentos sociais e a democracia. Desde $2013^{3}$ presenciamos a polarização dos discursos de ódio que culminam nesta eleição para Presidente da República (2018) num processo de questionamento da democracia e oposição de projetos para a sociedade. Ganha força a extrema-direita em seu discurso de ódio, violência, intolerância, racismo, misoginia, machismo, Igtbfobia, representado por um candidato claramente despreparado política e intelectualmente que ganha as massas pelo discurso de combate a corrupção, a violência e o apelo à moral e os bons costumes. Nos cenários estaduais, envolvendo governo e parlamentos, outros/as candidatos/as também expressam elementos presentes no pensamento conservador, destacando no debate político, propostas que demonstram proposições de ação, via Estado, na lógica da moralização e militarização da questão social.

A defesa desta perspectiva encontra no discurso moralizador e na retomada do apelo aos valores tradicionais cristãos como orientadores do convívio social, quer seja pelo estabelecimento de regras morais de convivência ou pela materialização de tais regras na legislação e nas políticas sociais, o solo fértil para o retorno a defesa de um Estado que deve se pautar pelas "leis divinas". E, neste sentido, as instituições e o Estado passam a nos demandar como profissão o controle, o reenquadramento e a correção moral.

São tempos desafiadores para pensarmos a profissão e a defesa dos valores expressos na construção de uma ética emancipatória que vimos realizando nas últimas quatro décadas enquanto categoria profissional. Nesse sentido, acreditamos que é imperativo discutirmos um aspecto presente centralmente no pensamento conservador: a relação do Estado e suas instituições com a religião, e, consequentemente, a questão da influência dos valores

\footnotetext{
${ }^{2}$ Sobre o enovelamento da discussão de classe, gênero e raça/etnia ver Cisne e Santos (2018).

3 Uma análise dos eventos deste momento no Brasil pode ser encontrada em Maricato [et al.] (2013).
} 


\section{tempordilis}

religiosos no exercício profissional do/a assistente social como expressão do conservadorismo.

É imperativo, construirmos como categoria, a defesa da laicidade do Estado (o que inclui nossa atuação em suas instituições, no planejamento e execução das políticas sociais), como uma das formas de enfrentamento do conservadorismo na atualidade.

\section{A EXPRESSÃO DO CONSERVADORISMO NA PRETENSA LAICIDADE DE ESTADO NO BRASIL}

Ao reiterarmos que são tempos radicalmente desafiadores, afirmamos também que é preciso defender o óbvio para afirmar nosso Projeto Ético-Político de profissão. Assim, não é tempo de recuo e sim de ousadia, e a oferta desta reflexão pela racionalização da polêmica que entorna a questão da laicidade de Estado inclui falar, também, sobre religião entre assistentes sociais, pois do ponto de vista histórico-concreto, ainda estamos em processo de secularização, de desconstrução de aspectos culturais e de senso comum que ainda nos vincula com o imaginário religioso (TONET, 2016, p. 66-69).

O debate da laicidade de Estado, até o final do século 20, repousava apenas no âmbito da educação, em face da não-obrigatoriedade do ensino religioso nas escolas públicas, e dos símbolos religiosos em repartições públicas. Hoje, porém, os desafios trazidos pela atual ofensiva conservadora expõem desdobramentos para as políticas públicas e para o Serviço Social que não mais nos permitem a secundarizar a laicidade, dado ela ser um dos pilares da concepção moderna de República ${ }^{4}$, conquistado e aprimorado principalmente no contexto entre as revoluções francesa e industrial.

O secularismo, enquanto pressuposto fundamental do arcabouço ideológico nos campos econômico, filosófico, cultural e moral das construções revolucionárias daquela época, também inspirou a concepção de laicidade perante a necessidade de desmistificação da compreensão jurídica do aparato estatal que então estava sendo erguido. $O$ distanciamento da visão religiosa de mundo pela sociedade estabelece, portanto, a secularização como um adentrar na história, assentado em bases científicas e pelo domínio público (HOBSBAWM, 2006, p. 306-309).

Não é de menos ressaltar a importância de compreender a etimologia do que seja a laicidade, significando qualidade de ser laico, enquanto expressão oriunda do grego laikós (que significa do povo), indicando uma construção jurídico-política na defesa da sociabilidade secular, sem a influência de valores religiosos no âmbito público, ou seja, que se coloca historicamente em contraposição legítima à vida social controlada pelo âmbito canônico ou religioso em geral. Temos, portanto, um desdobramento em três dimensões fundamentais que informam a tradução histórica da laicidade de Estado e da secularização da sociedade, no âmbito do

\footnotetext{
${ }^{4}$ Uma análise historiográfica minuciosa do processo de secularização da França, como principal referência de construção de um modelo laico de estado-república, pode ser conhecida em ZUBER (2010).
}

Temporalis, Brasília (DF), ano 18, n. 36, p. 45-64, jul./dez. 2018. ISSN 2238-1856 
Direito Internacional ${ }^{5}$, explicando de forma mais cristalina, a laicidade como um conjunto de valores ético-políticos:

- Separação entre Estado e Clero, posição política, enquanto noção do público científico acima do privado moral, oriundo das religiões institucionais;

- Liberdade Religiosa, enquanto garantia das manifestações religiosas em sociedade, nos âmbitos público e privado, bem como a previsão de alguns direitos às instituições religiosas, a partir de suas conformações seculares;

- Liberdade de Consciência, enquanto direito individual de constituir sua própria e singular base de conhecimento, valores, crenças e não-crenças, em face dos demais valores da laicidade;

Um Estado comprometido com a laicidade deveria garantir à sociedade e aos seus indivíduos estas três dimensões de maneira integral, horizontal e interdependente. Entretanto, as razões de fundamento histórico trazidos na primeira parte deste artigo nos permitem afirmar quehá uma capitulação burguesa da laicidade de Estado, distorcendo essas dimensões em função da necessidade de se instrumentalizar o princípio da laicidade para seus propósitos de dominação de classe. Essa distorção, no geral, traz o entendimento equivocado de que a laicidade do Estado seria tão somente a ampliação e aprofundamento da Liberdade Religiosa, posicionando a Liberdade de Consciência e a Separação entre Estado e Religião como subsidiárias da mesma6.

Assim, se torna importante diferenciar os quatro tipos de Estado7 em face da laicidade, que temos como exemplos atuais de organização:

- Estado Teocrático: Desprovido de laicidade e governado pelo monarca ou chefesupremo da religião oficial. Ex: Arábia Saudita, Irã e Vaticano;

- Estado Confessional (duas vertentes): Uma vertente seria o Estado governado por civil ou monarquia parlamentar, mas sem separação entre Estado e religião, sendo que a moral religiosa é compreendida, inclusive de forma legal, com restrições à secularização. Ex: Israel, Líbano, Paquistão, Afeganistão, Iraque, Camboja, Tailândia, Myanmar, Malásia e boa parte de países africanos de cultura árabe. Na outra vertente, o país é governado por civil, porém, com religião oficial como protoforma histórica e com variada e relativa influência nas leis, a depender do processo de secularização. Ex: Países nórdicos, Argentina, Grã-Bretanha, Grécia;

- Estado Ateu: Estado não reconhece (ou somente reconhece parcialmente) a liberdade religiosa no âmbito público, mas relativiza sua prática no âmbito doméstico. Ex: China, Coréia do Norte, Vietnã, Laos;

- Estado Laico: Compreende a maioria dos países no mundo. Combina separação entre Estado e Religião com liberdade religiosa e de consciência, configurando

\footnotetext{
${ }^{5}$ Uma exposição sobre a conformação histórica no Direito internacional pode ser conferida em CABRAL (2009).

${ }^{6}$ Lacerda (2009) explana sobre essas diferenças, apontando pistas de construção crítica sobre a laicidade vigente no Brasil.

${ }^{7}$ Ranquetat Jr (2009) apresenta diferenciação de conceitos de laicidade, secularização e laicismo, contribuindo para a compreensão inicial sobre a conformação de alguns países, em face da laicidade de Estado.
} 
diversos formatos congruentes com a relação histórico-concreta que cada país tem com as religiões. Exemplos de países onde a laicidade é mais íntegra são: França, Cuba, Uruguai, Japão. Exemplos de países onde a laicidade é mais frágil são: Brasil, Estados Unidos, Espanha, Alemanha, Holanda, Bélgica, Itália, Rússia, Índia e boa parte dos países da América Latina e Central;

Ao analisar o exemplo brasileiro constatamos que, como em vários países, não tivemos um processo revolucionário concreto que anunciasse a laicidade como pressuposto de ruptura com o feudalismo e com o autoritarismo imperial de cunho eclesiástico, impossibilitando que a sociabilidade brasileira se desenvolvesse a partir de uma sobreposição radical da ordem burguesa à ordem eclesiástica. Esta opção resignificou culturalmente o fracasso político do Império em gerir os anseios burgueses que emanaram das revoluções, diante da necessidade de se fundar uma república capaz de perpetuar, ao máximo possível, as bases de exploração do trabalho e da moralidade pública.

Nesta seara, nos parece que a liberdade religiosa no Brasil, no contexto da República, é capitulada pela burguesia como liberdade da maioria religiosa, isto é, da maioria cristã (católica e evangélica), no caso, podendo certamente influenciar a sociabilidade brasileira mediante seus pressupostos morais de controle da família, do trabalho, da política, das políticas sociais, da arte e da consciência. Portanto, quando se discute laicidade no contexto brasileiro, essa premissa se faz presente, depreciando a importância da sua compreensão com base na sua totalidade. Para o que interessa ao debate, neste momento, podemos trazer um breve recorte de como a laicidade é contextualizada historicamente na constituição do Estado brasileiro, a partir do próprio instrumento legal da Constituição Federal e outros instrumentos jurídicos.

Nas Constituições brasileiras de 1822 e 1824 (Brasil Império/Feudalismo), verificamos a introdução de princípios do Estado liberal, mas com manutenção do catolicismo como religião oficial e as crenças diferentes da católica restritas ao ambiente doméstico.

O documento de 1891 (República Velha) separa legalmente o Estado do Clero, mas reconhece a Santa Sé (futuro Estado do Vaticano) como instância diplomática; prevê a manifestação pública de crenças e a associação para isso. No entanto, uma reforma é feita em 1926, retrocedendo para o controle baseado na "moral pública".

No documento que conforma o Estado Novo (Era Vargas), em 1934 ${ }^{8}$, é mantida a separação Estado/Clero, mas com abertura para a colaboração "em prol do interesse coletivo". Surge no texto a concepção de liberdade de consciência, mas vinculada ao respeito à "ordem pública e aos bons costumes", assim como o casamento indissolúvel e a concepção de família heteronormativa.

\footnotetext{
${ }^{8}$ Nesta época também se dá a reação católica contra a secularização no Brasil, as bases legais e políticas para racionalização da Assistência Social e a gênese do Serviço Social (CARVALHO; IAMAMOTO, 2008, p. 125-164).
}

Temporalis, Brasília (DF), ano 18, n. 36, p. 45-64, jul./dez. 2018. ISSN 2238-1856 


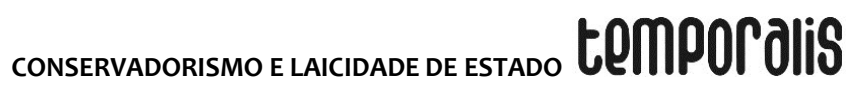

Ainda na Era Vargas, uma específica alteração em 1937, capitula 1934 com o preâmbulo: "Atendendo ao Estado de apreensão criado no País pela infiltração comunista, que se torna dia a dia mais extensa e mais profunda, exigindo remédios, de caráter radical e permanente" (BRASIL, 1937). Adiciona-se a esta leitura política fundamentalista e razoavelmente pautada no fascismo, a previsão do ensino religioso eletivo na escola pública, sendo suprimida a concepção de liberdade de consciência, em face do enfoque na liberdade religiosa. Tais premissas foram aperfeiçoadas em $1946^{9}$, ampliando as isenções fiscais às instituições religiosas.

No período da Autocracia Burguesa ${ }^{10}$, temos o texto legal de $1967^{11}$, aprimorando o de 1946 e institucionalizando a delegação de poder público aos serviços de educação, assistência e saúde para as entidades religiosas. Já em 1969² , com uma Constituição sob emenda única, ocorre a legitimação da legalidade militar e ditatorial, prevendo a liberdade de consciência ainda sob respeito à ordem pública e aos bons costumes.

Na última e atualmente vigente Constituição Federal de $1988^{13}$, encontramos a liberdade de consciência pela primeira vez desvinculada do respeito à ordem pública e aos bons costumes. Porém, ocorre mais um aperfeiçoamento das isenções fiscais para instituições religiosas e qualificação dos convênios para execução de políticas públicas. Este documento abre este último período, dando as bases de leitura da realidade concreta acerca da situação atual da laicidade brasileira.

Posterior a última Constituinte, tivemos no Governo FHC (1994 a 2002) a suplantação da Legião Brasileira de Assistência (LBA) pelo Programa Comunidade Solidária, fomentando e legalizando a terceirização das políticas públicas na direção de entidades religiosas ${ }^{14}$.

No Governo Lula (2003 a 2010) se pôde observar o desvirtuamento do Programa Nacional de Direitos Humanos 3 (PNDH 3) ${ }^{15}$, que previa o fomento da laicidade de Estado em várias esferas de direitos sociais. Tal movimento resultou no recuo em pautas caras aos movimentos de Direitos Humanos, expressas na primeira versão do programa e, principalmente,no Acordo

\footnotetext{
9 Estabelecimento do primeiro Código de Ética de Assistentes Sociais de 1947, tendo a fé cristã como fundamento ético, ou seja, uma profissão não laica, assegurada por um Estado Laico (ASSOCIAÇÃO BRASILEIRA DE ASSISTENTES SOCIAIS, 1947). Isto significou o fomento de uma profissão para enfrentar a laicidade de Estado, conforme os interesses conservadores e do capital.

${ }^{10}$ Nestes termos, compreende-se que o processo vivenciado no Brasil circunscrito ao período de 1964 a 1984 não foi apenas uma ditadura militar, mas sobretudo, uma ditadura da burguesia. Sobre este conceito, ver Florestan Fernandes (2005).

${ }^{11 E d i t a d o ~ o ~ C o ́ d i g o ~ d e ~ e ́ t i c a ~ p r o f i s s i o n a l ~ d e ~ 1965, ~ c o m b i n a n d o ~ n e o t o m i s m o ~ c o m ~ a ~ t r i ́ a d e ~ a u t o r i t a ́ r i a ~ e ~ t e c n i c i s t a ~ d e ~}$ Caso/Grupo/Comunidade (CONSELHO FEDERAL DE ASSISTENTES SOCIAIS, 1975);

${ }^{12}$ Estabelecido o Código de ética de 1975, reforçando a defesa da família, do equilíbrio e da integração social (CONSELHO FEDERAL DE ASSISTENTES SOCIAIS, 1975).

${ }^{13}$ Editado o Código de Ética de 1986, como o primeiro código que questiona o autoritarismo de Estado e lança bases para o exercício profissional que se abstém de controlar a família por razões morais públicas, tendo a democracia e a cidadania como pressupostos principais (CONSELHO FEDERAL DE ASSISTENTES SOCIAIS, 1986).

${ }^{14}$ Maria Ozanira da Silva e Silva (2001) apresenta análise crítica do Programa Comunidade Solidária.

${ }^{15}$ Uma análise geral das polêmicas em torno do PNDH 3 pode ser conferida em Adorno (2010).
} 


\section{temporalis}

Brasil-Vaticano (BRASIL, 2010), que reiterou e ampliou as garantias para a Igreja Católica dentro do Estado brasileiro.

O Governo Dilma (2010-2016) além de não retomar o PNDH 3 original, deu sequência ao recuo das gestões anteriores, vetando a introdução de conteúdo que aborda a diversidade sexual na educação, bem como recuou na defesa do aprimoramento da legalização do aborto e estabeleceu ampliação das concessões de rádio e TV para interesses religiosos. Também na área da saúde, assistimos o desenvolvimento do Programa Crack: é possível vencer, sob o fomento às Comunidades Terapêuticas, ampliando a depreciação da saúde mental pela via do financiamento de ações religiosas.

Sob importante vigor político, a bancada evangélica na Câmara e no Senado (Frente Parlamentar Evangélica) segue apoiando o presidente Michel Temer após o Impeachment da presidenta Dilma Rousseff, em meados de 2016, ameaçando frontalmente a moribunda laicidade brasileira, com iniciativas que vão desde uma série de projetos de $l \mathrm{i}^{16}$, passando pelas intervenções dos deputados federais quando da votação do próprio processo de impeachment da presidenta Dilma, em 17 de Abril de 2016, onde evocavam o impedimento sob o reestabelecimento de valores morais como família e propriedade.

O último episódio, que apresenta mais uma derrota à laicidade brasileira se deu em julgamento da ADI 4439 pelo Supremo Tribunal Federal (STF), em 27 de setembro de 2017, oportunidade em que, por seis votos a cinco (sendo o último voto o de minerva da então presidente da corte, a Ministra Cármen Lúcia), autoriza no Brasil, o ensino religioso confessional nas escolas públicas, de modo que poderá ser professado por representantes das próprias instituições religiosas (sem interferência do Estado) e não mais constar apenas como ensino da história das religiões, sob abordagem laica, ainda que respeitada a faculdade de escolha dos/as estudantes. Tal sentença ${ }^{17}$ avaliza peremptoriamente o acordo realizado entre Brasil e Vaticano, pelo Governo Lula, conforme mencionamos acima.

Em suma, podemos perceber que o Estado brasileiro parece controlar a laicidade com rédeas, conforme as exigências políticas burguesas de cada tempo histórico, promovendo reprodução ideológica, aprovando leis e direcionamentos de políticas sociais em consonância com a religiosidade cristã, reafirmando uma sociabilidade constituída por preconceitos e estigmatizações com base na fé.

\footnotetext{
${ }^{16}$ A bancada parlamentar fundamentalista se constitui de forma mais orgânica ao final do Governo Lula, em 2010, em reação ao Acordo Brasil-Vaticano, se valendo da proposta de Estatuto da Liberdade Religiosa (PL 1219/2015) e de outros projetos de lei contrários à afirmação e aprofundamento da laicidade de Estado. Os projetos de Lei expressam, ao mesmo tempo, a reprodução e radicalização da captura da laicidade pelo capital e pela moralidade religiosa, bem como as expressões que visualizamos nas políticas públicas, no cotidiano de assistentes sociais. Podemos verificar isso nas proposituras e Aumento doPoder perante STF (PEC 99/2011); Estatuto da Família (PL 6583/13); Estatuto do Nascituro (PL 478/2007); Abertura para violência com base no fundamentalismo (PL 6314/2005) e outros semelhantes.

${ }^{17}$ Uma abordagem do Direito, crítica ao ocorrido pode ser conferida em lotti (2017).
}

Temporalis, Brasília (DF), ano 18, n. 36, p. 45-64, jul./dez. 2018. ISSN 2238-1856 


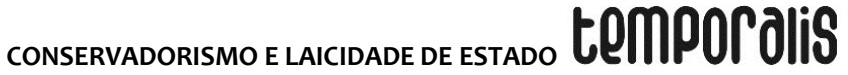

\section{A DEFESA DA LAICIDADE PROFISSIONAL ENQUANTO COERÊNCIA ÉTICA E ENFRENTAMENTO AO CONSERVADORISMO}

A trajetória do Serviço Social no Brasil é atravessada por sua estreita relação com o conservadorismo. Sua gênese se dá no contexto de aprofundamento da questão social com a necessidade de um profissional demandado pelo Estado a apaziguar os conflitos provenientes da relação Capital/Trabalho. A Igreja Católica assume a formação deste profissional, criando as primeiras faculdades de Serviço Social no Brasil. Assim, em sua origem, o conteúdo de formação dos/as assistentes sociais tem por fundamento o pensamento social da Igreja Católica com ênfase na perspectiva neotomista.

Forma-se, portanto, a partir de sua gênese, um ethosprofissional ${ }^{18}$ conservador que se expressará no conjunto de legislações e orientações profissionais ${ }^{19}$ produzidas no período de 1936 a $1982^{20}$, direcionando a atuação e formação dos/as assistentes sociais numa perspectiva conservadora durante quase cinco décadas.

Essa referência ética elege valores humanista-cristãos, como pessoa humana,
perfectibilidade da pessoa humana, bem comum, autodeterminação e integração
social, orientando a ação profissional ao enquadramento, ajustamento e correção das
condutas de maneira disciplinadora, em uma abordagem focada na individualização e
moralização da questão social, em consonância com o ethosburguês e sob forte
influência da doutrina social da Igreja Católica. Ele se traduz nos Códigos de Ética de
1947, de 1965 e de 1975, que trarão em seus artigos orientações claras para a atuação
profissional com base nesses valores e referências de intervenção (CARDOSO, 2013,
p. 166).

A década de 1980 marca a inflexão do Serviço Social para a defesa de valores emancipatórios. Em termos da ética profissional, o rompimento com o conservadorismo se expressará a partir do Código de 1986, demarcando o compromisso da profissão com a classe trabalhadora. Amplia seu compromisso com uma perspectiva emancipatória no Código de 1993, no qual,

Elege valores emancipatórios como liberdade, plena expansão dos indivíduos sociais, democracia, cidadania e equidade social, orientando a ação profissional à luta pela emancipação política e humana, em uma abordagem livre de preconceitos e juízos de valor, defendendo os direitos humanos contra toda e qualquer forma de discriminação e opressão, bem como na defesa dos direitos sociais. Para tanto, explicita ainda, o necessário compromisso profissional com a competência e o aprimoramento, e, ainda, com o usuário no jogo de correlação de forças institucionais (CARDOSO, 2013, p. 226).

\footnotetext{
${ }^{18} \mathrm{Um}$ modo de ser profissional que constitui a construção de uma determinada ética profissional direcionando o comportamento dos/as assistentes sociais.

19 Uma análise mais aprofundada sobre todos os Códigos de Ética pode ser vista em Barroco (2001) e Cardoso (2013). No item anterior apresentamos alguns elementos que exemplificam a perspectiva ética e política expressa em cada um deles.

${ }^{20}$ Ano em que se apresenta o primeiro documento oficial que expressará o rompimento com o conservadorismo na profissão: o Currículo Mínimo de 1982.
} 
Tal inflexão, no entanto, não eliminou o conservadorismo do interior da profissão. O Serviço Social brasileiro expressa claramente a hegemonia de um projeto profissional (chamado de Projeto Ético-Político) comprometido com essa perspectiva emancipatória há quase 40 anos, mas, como sabemos, hegemonia não significa homogeneidade, nem tão pouco maioria. E, em tempos de radicalização do conservadorismo, este ganha força e explicitação também no interior da profissão. Não somos uma bolha!

O pensamento conservador tem nas religiões um espaço fértil de produção, reprodução e disseminação. Neste sentido, a defesa ética expressa em nosso atual Código é clara no que se refere ao exercício profissional ter um caráter laico e compromissado com valores emancipatórios.

Já na Introdução do Código de Ética atual (CONSELHO FEDERAL DE SERVIÇO SOCIAL, 2011) e em seus Princípios Fundamentais, podemos ler:

A história recente da sociedade brasileira, polarizada pela luta dos setores democráticos contra a ditadura e, em seguida, pela consolidação das liberdades políticas, propiciou uma rica experiência para todos os sujeitos sociais [...].Particularmente para as categorias profissionais, esta experiência ressituou as questões do seu compromisso ético-político e da avaliação da qualidade dos seus serviços.

Nestas décadas, o Serviço Social experimentou, no Brasil, um profundo processo de renovação. $\mathrm{Na}$ intercorrência de mudanças ocorridas na sociedade brasileira com o próprio acúmulo profissional, o Serviço Social se desenvolveu teórica e praticamente, laicizou-se, diferenciou-se e, na entrada dos anos noventa, apresenta-se como profissão reconhecida academicamente e legitimada socialmente.

[este movimento] partiu da compreensão de que a ética deve ter como suporte uma ontologia do ser social: os valores são determinações da prática social, resultantes da atividade criadora tipificada no processo de trabalho. É mediante o processo de trabalho que o ser social se constitui, se instaura como distinto do ser natural, dispondo de capacidade teleológica, projetiva, consciente; é por esta socialização que ele se põe como ser capaz de liberdade. Esta concepção já contém, em si mesma, uma projeção de sociedade - aquela em que se propicie aos/às trabalhadores/as um pleno desenvolvimento para a invenção e vivência de novos valores, o que, evidentemente, supõe a erradicação de todos os processos de exploração, opressão e alienação. É ao projeto social aí implicado que se conecta o projeto profissional do Serviço Social - e cabe pensar a ética como pressuposto teórico-político que remete ao enfrentamento das contradições postas à profissão, a partir de uma visão crítica, e fundamentada teoricamente, das derivações ético-políticas do agir profissional.

PRINCIPIOS FUNDAMENTAIS

1- Reconhecimento da liberdade como valor ético central e das demandas políticas a ela inerentes - autonomia, emancipação e plena expansão dos indivíduos sociais;

2- Defesa intransigente dos direitos humanos e recusa do arbítrio e do autoritarismo; 8- Opção por um projeto profissional vinculado ao processo de construção de uma nova ordem societária, sem dominação, exploração de classe, etnia e gênero (CONSELHO FEDERAL DE SERVIÇO SOCIAL, 2011, grifo nosso). 
Embora não haja no atual Código de Ética ${ }^{21}$ (CONSELHO FEDERAL DE SERVIÇO SOCIAL, 2011) dispositivo disciplinando o vínculo expresso com a devida laicidade profissional, esta tem sua garantia alicerçada nas disposições sobre a relação com os/as usuários/as do Serviço Social, bem como com as instituições empregadoras e com as entidades da categoria e da sociedade civil. usuários/as:

[...] Art. $5^{\circ}$ São deveres do/a assistente social nas suas relações com os/as

[...]

b- garantir a plena informação e discussão sobre as possibilidades e consequências das situações apresentadas, respeitando democraticamente as decisões dos/as usuários/as, mesmo que sejam contrárias aos valores e às crenças individuais dos/as profissionais, resguardados os princípios deste Código;

[...]

Art. $8^{\circ}$ São deveres do/a assistente social:

$[\ldots]$

b- denunciar falhas nos regulamentos, normas e programas da instituição em que trabalha, quando os mesmos estiverem ferindo os princípios e diretrizes deste Código, mobilizando, inclusive, o Conselho Regional, caso se faça necessário;

$[\ldots]$

Art. 13 São deveres do/a assistente social:

a- denunciar ao Conselho Regional as instituições públicas ou privadas, onde as condições de trabalho não sejam dignas ou possam prejudicar os/as usuários/as ou profissionais;

b- denunciar, no exercício da Profissão, às entidades de organização da categoria, às autoridades e aos órgãos competentes, casos de violação da Lei e dos Direitos Humanos, quanto a: corrupção, maus tratos, torturas, ausência de condições mínimas de sobrevivência, discriminação, preconceito, abuso de autoridade individual $e$ institucional, qualquer forma de agressão ou falta de respeito à integridade física, social e mental do/a cidadão/cidadã (CONSELHO FEDERAL DE SERVIÇO SOCIAL, 2011, grifos nossos).

Portanto, a possibilidade de negação em relação ao inerente e irrevogável caráter laico do exercício profissional, se põe como expressão desse conservadorismo, na medida em que o atravessamento do exercício profissional pelas crenças religiosas dos/as assistentes sociais reedita a premissa de que a sua liberdade religiosa singular pode compor o fazer profissionalassim como a liberdade religiosa pode se sobrepor à laicidade de Estado. Nesta esteira, a pesquisa de Alves (2017) nos traz uma abordagem que mostra o Serviço Social sendo contemporaneamente desafiado em sua laicidade de formação e exercício profissional por influências diretas e indiretas de forças sociais e políticas ligadas ao preterimento da qualificação da ética profissional e do aperfeiçoamento da laicidade de Estado.

Coerentemente com a posição assumida em nosso Código de Ética, no que tange ao Conjunto CFESS/CRESS ${ }^{22}$, observamos um crescente e firme posicionamento na garantia da laicidade de

\footnotetext{
${ }^{21}$ O livro Código de Ético do/a Assistente Social: Comentado (Barroco; Terra, 2012) traz adequada interpretação jurídico-política de cada dispositivo do documento, em face aos desdobramentos para esta discussão.

${ }^{22}$ Conselho Federal de Serviço Social (CFESS); Conselho Regional de Serviço Social (CRESS).
} 
Estado no âmbito da sua institucionalidade ${ }^{23}$, bem como no âmbito da categoria de assistentes sociais. Este posicionamento é inaugurado na Carta de Natal (CONSELHO FEDERAL DE SERVIÇO SOCIAL, 2007), compondo a expressão do posicionamento conjuntural da categoria no $36^{\circ}$ Encontro Nacional do Conjunto CFESS/CRESS de 2007. Entretanto, a matéria da laicidade de Estado somente figura nas deliberações do Conjunto a partir do $37^{\circ}$ Encontro Nacional, de 2008, seguindo presente até o $43^{\circ}$ Encontro Nacional, sem, no entanto, terem desdobramentos que cumprissem as deliberações até $2015^{24}$.

Nesta esteira, cumprindo a deliberação nacional, o Conselho Federal de Serviço Social (2015) se posiciona em âmbito nacional, problematizando e denunciando as ameaças conservadoras pelas quais passa a profissão e a sociedade brasileira, no que se refere a garantia plena da laicidade de Estado, o qual

[...] não pode tomar como referência para legislar sobre a vida dos indivíduos sociais concepções, convicções e valores fundados em dogmas religiosos. O ordenamento jurídico da vida social, os princípios, diretrizes e objetivos das políticas sociais (saúde, educação, assistência social, etc.), devem coadunar com a afirmação de liberdades individuais, como a de manifestação religiosa, política, de orientação sexual e de identidade de gênero. Assim como, o fortalecimento do Estado Democrático de Direitos supõe reconhecer que a intervenção estatal está limitada a interesses de caráter público e deve expressar o seu distanciamento e indiferença a convicções de bases confessionais (CONSELHO FEDERAL DE SERVIÇO SOCIAL, 2015).

A positiva repercussão dos posicionamentos acima mobilizou a categoria reunida no $46^{\circ}$ Encontro Nacional do Conjunto CFESS/CRESS a aprovar deliberação com vistas a "Realizar ações sobre Serviço Social e os temas de Estado laico, liberdade de consciência, liberdade religiosa e fundamentalismo religioso, com vistas à elaboração de subsídios sobre a incompatibilidade de se recorrer à religiosidade no exercício profissional [...]"(CONSELHO FEDERAL DE SERVIÇO SOCIAL, 2017, p.18), implicando ao Conjunto um caminho de debates e reflexões até o eventual posicionamento normativo definitivo sobre a matéria.

No âmbito da perspectiva hegemônica construída na profissão nestas quatro décadas, parecenos possível afirmar que a laicidade do exercício profissional tem sido afirmada, como vimos, tanto em nossa legislação profissional, quanto no posicionamento ético e político do conjunto de nossas entidades.

Por sua vez, podemos ler em documento do CRESS/SP (2016), a crescente adesão de profissionais ao trabalho voluntário (não-remunerado), em geral, legitimando intenções

\footnotetext{
${ }^{23} \mathrm{~A}$ Resolução CFESS n ${ }^{\circ}$ 627/2012 veda a utilização de símbolos, imagens e escritos religiosos nas dependências do Conselho Federal, dos Regionais e das Seccionais de Serviço Social (CONSELHO FEDERAL DE SERVIÇO SOCIAL, 2012). Já a experiência do Conselho Regional de Serviço Social da $9^{a}$ Região/SP, sob a Instrução Normativa CRESS/SP n ${ }^{\circ}$ 01/2015, dispõe Observação da laicidade de estado na escolha de locais para realização de reuniões, eventos e demais atividades do Conselho (CONSELHO REGIONAL DE SERVIÇO SOCIAL DE SÃO PAULO, 2015).

${ }^{24}$ Tal fato nos faz refletir o quanto este é um árduo debate, repleto de resistências e tensionamentos para o conjunto da categoria, mas também nos demonstra que conseguimos avançar no enfrentamento a estes tensionamentos.
} 
institucionais precarizantes do estágio profissional e contrárias à laicidade. É citado também o aumento no número de denúncias éticas envolvendo violação da laicidade da profissão, das políticas públicas e da liberdade de consciência dos/as usuários/as como, por exemplo, não questionar e até corroborar com violação da liberdade de consciência dos/as usuários/as no espaço onde trabalha; inserção de frases religiosas em formulários e outros instrumentais; uso de lemas religiosos no carimbo profissional; utilização de textos de auto-ajuda e religiosos como instrumental de direcionar o comportamento do/a usuário/a; participação e organização de grupos de oração com usuários antes, durante e depois dos atendimentos; utilização de trechos bíblicos como fundamento teórico em laudos e pareceres; policiamento do comportamento do/a usuário/a, se colocando como referência moral e religiosa no contexto de sua demanda social e outras condutas morais avessas aos princípios éticos atuais.

Percebemos, portanto, o grande desafio ético que temos. Entendemos que uma das formas de enfrentamento ao conservadorismo na profissão é o aprofundamento da discussão da laicidade do exercício profissional e a defesa da laicidade do Estado (responsável pela elaboração e execução das políticas sociais com as quais trabalhamos). Destarte, podemos afirmar que se faz imperativo travarmos este debate no âmbito da formação profissional (na graduação e nos processos continuados de formação) e nos espaços políticos de representação da categoria.

\section{CONSIDERAÇÕES FINAIS}

Como pudemos ver no decorrer deste artigo, o conservadorismo moderno desde sua gênese, defende a unidade entre Estado e religião, compreendendo o Estado como um legado divino que, portanto, deve seguir as leis de Deus. Estas leis fundamentam-se numa perspectiva ahistórica e imutável de compreensão do homem/mulher e da sociedade, com base na defesa da tradição, da ordem, da harmonia, da propriedade privada e das desigualdades sociais.

Enquanto humanidade, no entanto, construímos a possibilidade de rompimento desta unidade Estado-religião e novos patamares civilizatórios, com a secularização da sociedade e a laicidade do Estado. Sabemos, porém, que a força e o poder da moral cristã, exercem ainda grande influência sobre as sociabilidades e forma de organização das diferentes sociedades, atrelada aos interesses do capital.

Neste sentido, o Estado brasileiro, embora assuma sua laicidade na Constituição Federal, não a realiza de fato. A religião cristã está representada politicamente em nosso Congresso, legislando sobre a vida dos/as brasileiros/as. Diferentes legislações e políticas sociais são votadas, aprovadas (ou negadas) e elaboradas, tendo por fundamento os valores religiosos. As instituições públicas carregam representações cristãs. Os profissionais (das diferentes áreas) que atuam nestas instituições têm discursos que remontam os valores de sua fé. Dentre tais profissionais, situam-se os/as assistentes sociais.

No âmbito da profissão, no entanto, avançamos neste debate e no enfrentamento ao conservadorismo. Nossa história demonstra a importante inflexão que realizamos de uma 


\section{temporalis}

ética conservadora a uma ética emancipatória. E, nesta perspectiva, temos nos posicionado na defesa da laicidade do Estado e do exercício profissional. Tal defesa está expressa em nosso atual Código de Ética e nas resoluções do conjunto CFESS/CRESSa partir de 2007, ganhando materialidade em documento próprio sobre esta discussão em 2015. Acreditamos, no entanto, que é imperativo seguirmos avançando.

A defesa da laicidade do Estado e do exercício profissional situa-se na relação direta com a defesa do princípio central anunciado em nosso Código: a liberdade. Situa-se também, como uma forma direta de enfrentamento ao conservadorismo.

É importante frisar que compreender o caráter laico do exercício profissional não tem a ver com negar a liberdade de consciência e a liberdade religiosa dos/as profissionais, mas sim garantir que tanto profissionais como os/as usuários/as tenham o direito a estas liberdades, não havendo submissão ou subjugação destes àqueles, uma vez que os/as profissionais encontram-se num lugar de poder em relação à população atendida.

Acreditamos, neste sentido, que a defesa da plenitude da laicidade é inerente ao estatuto ético da profissão, revestindo-a também deste caráter laico. Portanto, o exercício profissional que nega esta condição, não só viola flagrantemente o Código de Ética, como também capitula o retrocesso da sociabilidade em patamares medievais.

A laicidade do Estado brasileiro deve ser erguida como bandeira de luta dos/as assistentes sociais comprometidos/as com a materialização do Projeto Ético-Politico da profissão, bem como instrumento político fundamental no combate ao conservadorismo em nossa sociedade, na medida em que parametriza os limites entre a totalidade social e singularidade do ser social.

Sabemos, pois, que a luta pela emancipação humana não se restringe a defesa da laicidade do Estado, ao contrário, como nos aponta Marx (1991), trata-se da supressão do Estado burguês. No entanto, em tempos de radicalização do conservadorismo, acreditamos que a defesa de sua laicidade se faz urgente na perspectiva da emancipação política, em coerência com os valores por nós defendidos enquanto projeto profissional e expressos em nosso Código de Ética. Urge radicalizarmos também a defesa da emancipação política!

Nosso desafio no tempo presente se dá no enfrentamento rigoroso ao conservadorismo moral, afirmando que nossa profissão e nosso Projeto Ético-Político têm lado, e que esse lado não é o da ordem burguesa de controle moral pela religiosidade. Estamos do lado da materialização da liberdade como valor central vinculado às conquistas históricas que informam a possibilidade, também histórica, de contribuirmos com a construção de um projeto societário onde a moralidade será em função da riqueza humana apropriada pelos trabalhadores/as para reverter tudo o que nesta sociabilidade nos desumaniza (CARLI, 2015, p. 102). 
CONSERVADORISMO E LAICIDADE DE ESTADO

\section{REFERÊNCIAS}

ADORNO, Sérgio. História e desventura: $03^{\circ}$ Programa Nacional de Direitos Humanos.

Revista Novos Estudos, São Paulo - CEBRAP, n. 86, pp. 5-20, 2010.Disponível em:

<http://www.scielo.br/pdf/nec/n86/n86a01.pdf >. Acessado em 05 de set. de 2018.

ALVES, Luciano. Trabalho Voluntário no Serviço Social: Precarização sob roupagem ética da caridade. Revista EmancIPA: O Cotidiano em Debate/Revista do Conselho Regional de Serviço Social de São Paulo - CRESS 9 a Região. Número 2. São Paulo, 2017, pp. 44-65.

ASSOCIAÇÃO BRASILEIRA DE ASSISTENTES SOCIAIS. Código de Ética Profissional dos Assistentes Sociais (1947). São Paulo,1947. Disponível em: $<$ http://www.cfess.org.br/arquivos/CEP_1947.pdf >. Acesso em: 06 de setembro de 2018.

BARROCO, Maria Lúcia. Não passarão! Ofensiva neoconservadora e Serviço Social. REVISTA SERVIÇO SOCIAL E SOCIEDADE, n. 124, São Paulo, Cortez, 2015. Disponível em: $<$ http://www.scielo.br/pdf/sssoc/n124/0101-6628-sssoc-124-0623.pdf $>$. Acesso em: 17 mar. de 2018.

BARROCO, Maria Lúcia. Ética e Serviço Social: fundamentos ontológicos. São Paulo: Cortez, 2001.

BARROCO, Maria Lúcia; TERRA, Sylvia Helena. Código de Ética do Assistente Social comentado. Organização do CFESS. São Paulo: Cortez, 2012.

BRASIL. Constituição dos Estados Unidos do Brasil (de 10 de novembro de 1937). Brasília (DF), nov. 1937. Disponível em:

<http://www.planalto.gov.br/ccivil_03/Constituicao/Constituicao37.htm>. Acesso em: 6 set. 2018.

BRASIL. Decreto $n^{\circ} 7107$ de 11 de fevereiro de 2010. Promulga o Acordo entre o Governo da República Federativa do Brasil e a Santa Sé relativo ao Estatuto Jurídico da Igreja Católica no Brasil, firmado na Cidade do Vaticano, em 13 de novembro de 2008. Brasília, 2010. Disponível em: <http://www.planalto.gov.br/ccivil_03/_ato2007-2010/2010/decreto/d7107.htm>. Acesso em: 6 set. 2018.

BURKE, Edmund. Reflexões sobre a revolução na França. In: Weffort, Francisco (org.). Os clássicos da política. Vol. 2. 10. ed. São Paulo: Ática, 2001.

CABRAL, Alex lan Psarski. A Proteção Internacional ao Direito à Liberdade de Consciência: O Sistema da ONU e o Sistema Europeu de Proteção aos Direitos do Homem. Revista Eletrônica de Direito Internacional, São Paulo, v. 5, p. 1-33, 2009. Disponível em: $<$ http://centrodireitointernacional.com.br/static/revistaeletronica/volume5/arquivos_pdf/sum ario/alex_cabral.pdf $>$. Acesso em: 5 set. 2018. 
CARDOSO, Priscila F. G. O projeto ético-político em tempos de radicalização do conservadorismo: resistência e intransigência na luta por emancipação. Emancipa: o cotidiano em debate, São Paulo: Revista do Conselho Regional de Serviço Social de São Paulo (CRESS 9 a região), n. 1, maio 2016.

CARDOSO, Priscila F. G. A perspectiva conservadora e o Serviço Social. Ética e Projetos Profissionais: os diferentes caminhos do Serviço Social no Brasil. Campinas: Papel Social, 2013.

CARLI, Ranieri. GyörgyLukács e a Crítica à Necessidade da Religião. Revista Crítica Marxista, Campinas: CEMARX/IFCH/UNICAMP, n. 41, p. 89-103, 2015. Disponível em:

$<$ https://www.ifch.unicamp.br/criticamarxista/arquivos_biblioteca/artigo2017_02_15_10_48_1 8.pdf>. Acesso em: 5 set. 2018.

CARVALHO, Raul de; IAMAMOTO, Marilda V. Relações Sociais e Serviço Social no Brasil esboço de uma interpretação histórico-metodológica. 25. ed. São Paulo: Cortez, 2008.

CONSELHO REGIONAL DE SERVIÇO SOCIAL (São Paulo). Instrução Normativa nº 001/2015. Ed. 2017. São Paulo, 2015. Disponível em: <http://cress-sp.org.br/wpcontent/uploads/2016/08/IN-001_2015-consolidada.pdf>. Acesso em: 6 set. 2018.

CONSELHO REGIONAL DE SERVIÇO SOCIAL (São Paulo). Jornal Ação, São Paulo, ed. 82, 2016. Disponível em: <http://cress-sp.org.br/wp-content/uploads/2016/05/JORNAL.ACAO_.82.pdf>. Acesso em: 6 set. 2018 .

CONSELHO FEDERAL DE ASSISTENTES SOCIAIS. Código de Ética Profissional dos Assistentes Sociais (1965). Rio de Janeiro, 1965. Disponível em:

<http://www.cfess.org.br/arquivos/CEP_1965.pdf >. Acesso em: 6 set. 2018.

CONSELHO FEDERAL DE ASSISTENTES SOCIAIS. Código de Ética Profissional dos Assistentes Sociais (1975). Rio de Janeiro,1975. Disponível em:

<http://www.cfess.org.br/arquivos/CEP_1975.pdf>. Acesso em: 6 set. 2018.

CONSELHO FEDERAL DE ASSISTENTES SOCIAIS. Código de Ética Profissional dos Assistentes Sociais (1986). Rio de Janeiro,1986. Disponível em: <http://www.cfess.org.br/arquivos/CEP_1986.pdf>. Acesso em: 6 set. 2018.

CONSELHO FEDERAL DE SERVIÇO SOCIAL. CFESS Manifesta: em defesa do estado laico. Ed. Especial. Brasília (DF), 2015. Disponível em: <http://www.cfess.org.br/arquivos/2015CfessManifesta-EstadoLaico-Site.pdf >. Acesso em: 6 set. 2018. 
CONSELHO FEDERAL DE SERVIÇO SOCIAL. Código de Ética dos/as Assistentes Sociais (1993). Ed. 2011. Brasília, 1993. Disponível em: < http://www.cfess.org.br/arquivos/CEP_CFESSSITE.pdf>. Acesso em: 6 set. 2018.

CONSELHO FEDERAL DE SERVIÇO SOCIAL. Relatório do $46^{\circ}$ Encontro Nacional do Conjunto CFESS/CRESS. Brasília, 2017. Disponível em: <http://www.cfess.org.br/arquivos/Relatorio46nacional2017Final.pdf $>$. Acesso em: 28 set.2018.

CONSELHO FEDERAL DE SERVIÇO SOCIAL. Resolução CFESS nº 627/2012. Brasília, 2012. Disponível em: <http://www.cfess.org.br/arquivos/Res.Cfess.627-2012.pdf >. Acesso em: 6 set. 2018.

FERNANDES, Florestan. A revolução burguesa no Brasil: ensaios de interpretação sociológica. 5.ed. 4.reimp. Rio de Janeiro, Globo, 2005.

HOBSBAWM, Eric. A era das revoluções. Europa 1789-1848. Rio de Janeiro: Paz e Terra, 2006.

IOTTI, Paulo. Supremo Rasga Estado Laico ao Permitir Ensino de Dogmas Religiosos em Escolas Públicas. Página “Justificando”, Portal Carta Capital, 2017. Disponível em: <http://justificando.cartacapital.com.br/2017/09/28/supremo-rasga-estado-laico-ao-permitirensino-de-dogmas-religiosos-nas-escolas-publicas/>. Acessado em 05 de setembro de 2018.

KINZO, Maria D’Alva Gil. Burke: a continuidade contra a ruptura. Weffort, Francisco (org.). Os clássicos da política. Vol. 2. 10. ed. São Paulo: Ática, 2001.

LÖWY, Michael. Conservadorismo e extrema-direita na Europa e no Brasil. Revista Serviço Social e Sociedade, n. 124, São Paulo, Cortez, 2015. Disponível em:

<http://www.scielo.br/pdf/sssoc/n124/0101-6628-sssoc-124-0652.pdf>. Acesso em: 28 set. 2018.

MARICATO, Ermínia [et al.]. Cidades Rebeldes: passe livre e as manifestações que tomaram as ruas do Brasil. 1 ed. São Paulo: Boitempo: Carta Maior, 2013.

MARX, Karl. A questão judaica. São Paulo: Moraes, 1991.

RANQUETAT Jr, Cesar A. Laicidade, Laicismo e Secularização: Definindo e Esclarecendo Conceitos. Revista Sociais e Humanas - UFSM, [S.I.], v. 21, n. 1, p. 67-75, dez. 2009. ISSN 23171758. Disponível em: <https://periodicos.ufsm.br/sociaisehumanas/article/view/773/532>. Acesso em: 6 set. 2018.

SILVA, Maria Ozanira Silva e. O Comunidade Solidária: o não-enfrentamento à pobreza no Brasil. São Paulo: Cortez, 2001. 
TONET, Ivo. Marxismo, Religiosidade e Emancipação Humana. 1 ed. Maceió: Coletivo Veredas, 2016.

ZUBER, Valentine. A Laicidade Republicana em França ou os Paradoxos de um Processo Histórico de Laicização (séculos XVIII-XXI). Revista Ler História - ISCTE-IUL, v. 59, p. 161-180, 2010. Disponível em: <https://journals.openedition.org/lerhistoria/1370>. Acesso em: 20 set.2018. 